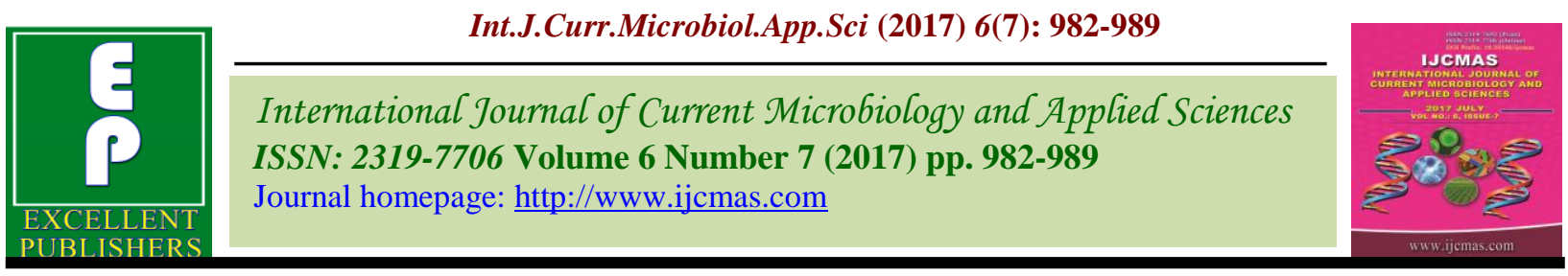

Original Research Article

https://doi.org/10.20546/ijcmas.2017.607.119

\title{
Diversity Analysis Based Upon Yield and its Contributing Traits in Fennel (Foeniculum vulgare L.)
}

\author{
Sumit Deswal*, T.P. Malik, S.K. Tehlan and Srikanth Mekala \\ Department of Vegetable Science, CCS Haryana Agricultural University Hisar-125004, India \\ *Corresponding author
}

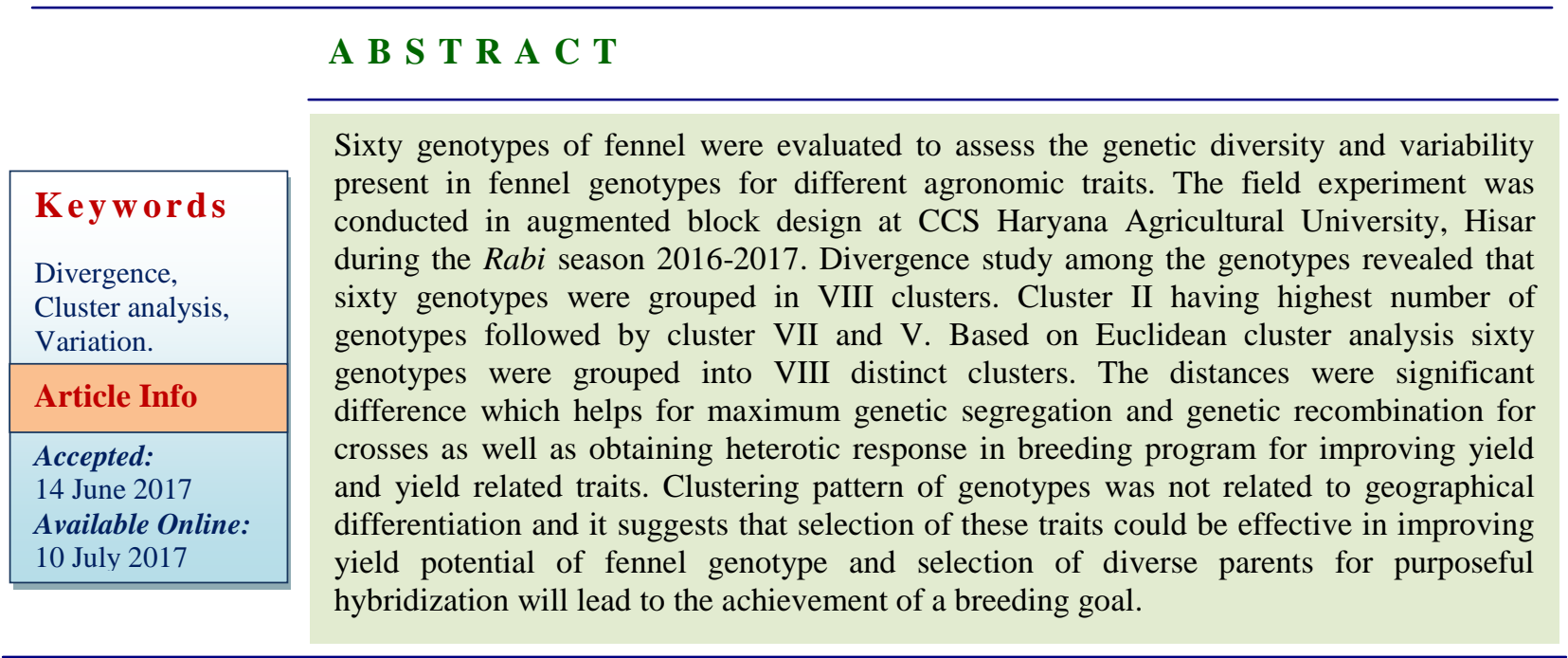

\section{Introduction}

Fennel (Sauf) belongs to the family Umbelliferae (Apiaceae) grown as seed crop in North Indian plains and it is a medicinal plant used as anti-spasmodic, appetite stimulant, stomatic, diuretic, anti inflammatory, anti diarrheic, against colic and as a lactation promoter (Neamatollahi et al., 2009). Availability of sufficient germplasm is a basic requirement for the genetic improvement of a crop. Germplasm has a pool of desirable traits in respect to yield, quality, biotic and abiotic stress resistance. Though many improved varieties of fennel have been released in the country, there is still ample scope for crop improvement by traditional and advanced methods of breeding to increase the adaptability and productivity of the crop.
Since most of the characters are quantitatively inherited and highly influenced by environment, it is difficult to judge whether the observation variability is heritable or not. Genetic diversity studies offers prospects for improvement of individual plant traits.

Genetic divergence analysis estimates the extent of diversity present among the studied genotypes and these studies could help the plant breeder in selecting the diverse parents for purposeful hybridization. Hence, the study was conducted to assess the genetic divergence and inter-relationship among the sixty genotypes of fennel for different yield attributes. 


\section{Materials and Methods}

The present experiment was carried out during Rabi season 2016-17 at Chaudhary Charan Singh Haryana Agricultural University, Hisar. The field experimental site was located at Vegetable Science farm, Hisar that is between $29.15^{\circ} \mathrm{N}$ latitude $75.69^{\circ} \mathrm{E}$ longitudes with a mean altitude of $215 \mathrm{~m}$ above msl. Sixty genotypes of fennel seeds were collected from different locations of India (Gujarat, Haryana and Rajasthan).These diverse genotypes were sown (13 November 2016) with Augmented block design having four blocks with fifteen entries in each block and having plot size of $3.0 \mathrm{~m} \times 1.0 \mathrm{~m}$ with spacing of $50 \mathrm{~cm} \times 20 \mathrm{~cm}$. All recommended agronomic practices were followed timely for successful raising the crop. Randomly five competitive plants were taken to record observation on eight quantitative characters namely plant height $(\mathrm{cm})$,primary branches per plant, secondary branches per plant, umbels per plant, umbellate per plant, seeds per umbellate, seeds per umbel and seed yield/plant(g). Euclidean cluster analyses (Spark, 1973) have been applied to assess genetic diversity and grouping of genotypes was done on the basis of minimum genetic distance using Wards (1963) minimum method.

\section{Results and Discussion}

Cluster analysis is the most basic method for estimating similarities and the objective of cluster analysis is to group the variables in to clusters such that elements within a analysis have a high degree of natural association among themselves while the cluster are relatively distinct from each other. The magnitude of $\mathrm{D}^{2}$ value suggested that there was considerable diversity in the genotypes of fennel. The range of variation allowed for grouping of sixty genotypes into VIII clusters based on data of yield and yield attributes (Table 1). The analysis of genetic diversity of fennel genotypes through the cluster analysis based on Euclidean distance (Ward, 1963) showed considerable amount of genetic diversity in the material. On the basis of relative magnitude of distances, 60 fennel genotypes were grouped into VIII clusters in such a way that the genotypes within the cluster had more similarity than the genotypes belonging to different clusters (Fig. 2). In general intra-cluster distances were relatively lower than inter-cluster distances showing that genotypes included within a cluster were genetically closer to each other than the genotypes included in different clusters (Table 2). Cluster VIII had smallest intracluster distance (1.420) while cluster VI had largest intra-cluster distance (3.213). Maximum intra-cluster distance (Fig. 1) was shown by cluster VII (3.213) followed by cluster II (2.788) followed by cluster IV (2.475), cluster VII (2.417), cluster I (2.384), cluster III (2.337), cluster V (2.283) and cluster I (1.420).Among the VIII clusters, maximum inter-cluster distance was shown by cluster VIII with two clusters namely; cluster VI (8.827) followed by cluster V (7.381). This shows that genotypes (Fig. 1) in cluster VII were more divergent than other clusters. In cluster VIII, genotypes showed higher yield per plant and cluster VI is characterized by having most of the agronomic traits such as primary branches per plant, umbellate per plant, seeds per umbellate, seeds per umbel and seed yield/plant (Table 3). Constellation of genotypes into different clusters based on yield and yield attributes was completely randomly at random and no relationship was observed between geographical origin and genetic diversity as the genotypes developed from different geographical region were included in the same clusters (Table 1). 
Table.1 Number of genotypes fallen in different clusters

\begin{tabular}{|c|c|c|}
\hline Clusters & No. of Genotypes & Genotypes \\
\hline $\mathrm{I}$ & 4 & HF-101,HF-103, HF-104, HF-105 \\
\hline II & 18 & $\begin{array}{l}\text { HF-102,HF-118, HF-123, HF-124,HF-196,HF-120,HF-129,HF-125,HF-130, HF-126,HF- } \\
\text { 127,HF-197,HF-121,HF-198,HF-199, } \\
\text { HF-200 }\end{array}$ \\
\hline III & 3 & HF-229,GF-2,Raj.Saurab \\
\hline IV & 5 & HF-122,HF-223, HF-207, HF-208,HF-209 \\
\hline $\mathrm{V}$ & 7 & HF-210,HF-222, HF-211, HF-220,HF-212,HF-225,HF-213 \\
\hline VI & 4 & HF-219,HF-226, HF-214, HF-228 \\
\hline VII & 16 & $\begin{array}{l}\text { HF-106,HF-108, HF-113, HF-114,HF-116,HF-115,HF-201,HF-202,PF-35, HF-107,HF- } \\
\text { 112,HF-203,HF-207 }\end{array}$ \\
\hline VIII & 3 & HF-109,HF-110, HF-111 \\
\hline
\end{tabular}

Table.2 Percent contribution of each trait toward divergence

\begin{tabular}{|l|c|c|}
\hline Traits & Times ranked first & Percent contribution toward divergence \\
\hline Plant Height $(\mathrm{cm})$ & 450 & 25.42 \\
\hline Number of primary branches per plant & 8 & 0.45 \\
\hline Number of secondary branches per plant & 38 & 2.15 \\
\hline Number of umbels per plants & 562 & 31.75 \\
\hline Number of umbellate per plant & 101 & 5.71 \\
\hline Number of seeds per umbellate & 4 & 0.23 \\
\hline Number of Seeds per umbel & 28 & 1.58 \\
\hline Seed yield/plant $(\mathrm{g})$ & 579 & 32.71 \\
\hline
\end{tabular}


Table.3 Average inter and intra clusters $\mathrm{D}^{2}$ values

\begin{tabular}{|l|l|l|l|l|l|l|l|l|}
\hline Clusters & Cluster I & Cluster II & Cluster III & Cluster IV & Cluster V & Cluster VI & Cluster VII & Cluster VIII \\
\hline Cluster I & 2.384 & 3.432 & 4.643 & 4.172 & 4.686 & 6.197 & 3.619 & 4.196 \\
\hline Cluster II & & 2.788 & 3.727 & 3.489 & 3.490 & 4.849 & 3.894 & 5.843 \\
\hline Cluster III & & & 2.337 & 4.765 & 5.033 & 5.770 & 3.889 & 5.960 \\
\hline Cluster IV & & & & 2.475 & 3.296 & 4.206 & 4.830 & 7.072 \\
\hline Cluster V & & & & & 2.283 & 3.608 & 5.168 & 7.381 \\
\hline Cluster VI & & & & & & 3.213 & 6.649 & 8.827 \\
\hline Cluster VII & & & & & & & & 2.417 \\
\hline Cluster VIII & & & & & & & & \\
\hline
\end{tabular}

Table.4 Cluster mean for different traits of fennel

\begin{tabular}{|l|c|l|l|l|l|l|l|l|}
\hline Clusters & $\begin{array}{c}\text { Plant } \\
\text { Height } \\
\text { (cm) }\end{array}$ & $\begin{array}{l}\text { Primary } \\
\text { branches }\end{array}$ & $\begin{array}{c}\text { Secondary } \\
\text { branches }\end{array}$ & $\begin{array}{c}\text { Umbels } \\
\text { per plant }\end{array}$ & $\begin{array}{c}\text { Umbellate } \\
\text { /Umbel }\end{array}$ & $\begin{array}{c}\text { Seeds per } \\
\text { umbellate }\end{array}$ & $\begin{array}{c}\text { Seeds per } \\
\text { umbel }\end{array}$ & $\begin{array}{c}\text { Seed } \\
\text { yield(g) }\end{array}$ \\
\hline Cluster I & 149.375 & 5.591 & 21.184 & 56.725 & 28.119 & 18.211 & 428.628 & 56.296 \\
\hline Cluster II & 158.529 & 8.699 & 27.306 & 63.316 & 31.118 & 17.444 & 447.443 & 63.282 \\
\hline Cluster III & 179.968 & 9.410 & 28.727 & 49.308 & 31.786 & 13.763 & 396.333 & 51.333 \\
\hline Cluster IV & 176.217 & 11.370 & 22.251 & 65.265 & 34.843 & 20.679 & 539.913 & 63.085 \\
\hline Cluster V & 153.554 & 10.559 & 31.354 & 65.940 & 32.238 & 21.218 & 602.280 & 69.940 \\
\hline Cluster VI & 162.022 & 11.554 & 27.188 & 65.457 & 35.964 & 23.354 & 639.438 & 78.693 \\
\hline Cluster VII & 142.010 & 10.224 & 24.086 & 46.965 & 23.915 & 14.663 & 396.735 & 49.138 \\
\hline Cluster VIII & 106.309 & 4.884 & 18.640 & 35.572 & 20.660 & 13.710 & 353.566 & 41.517 \\
\hline
\end{tabular}


Fig.1 Cluster diagram showing genetic divergence among the 8 clusters based on inter and intra clusters $\mathrm{D}^{2}$ values

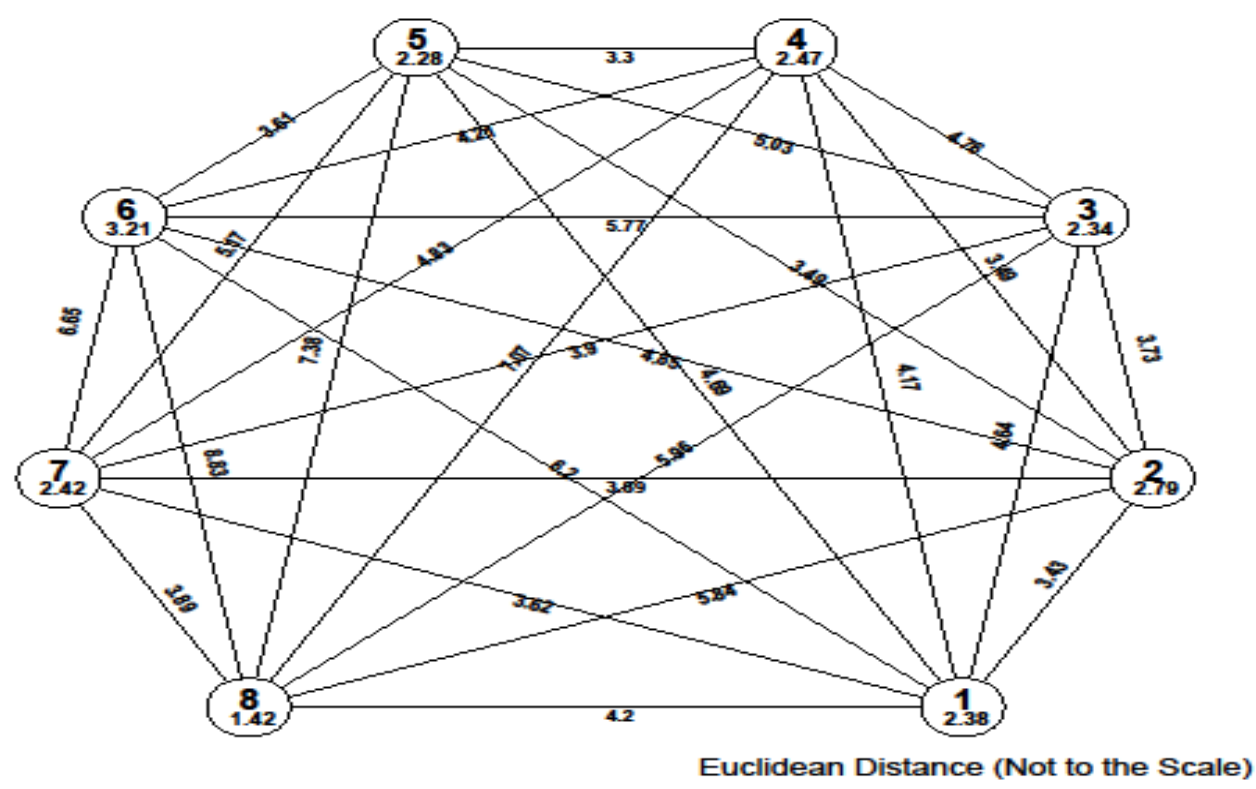


Fig.2 Dendrogram of 60 genotypes of Fennel based on Euclidean distance

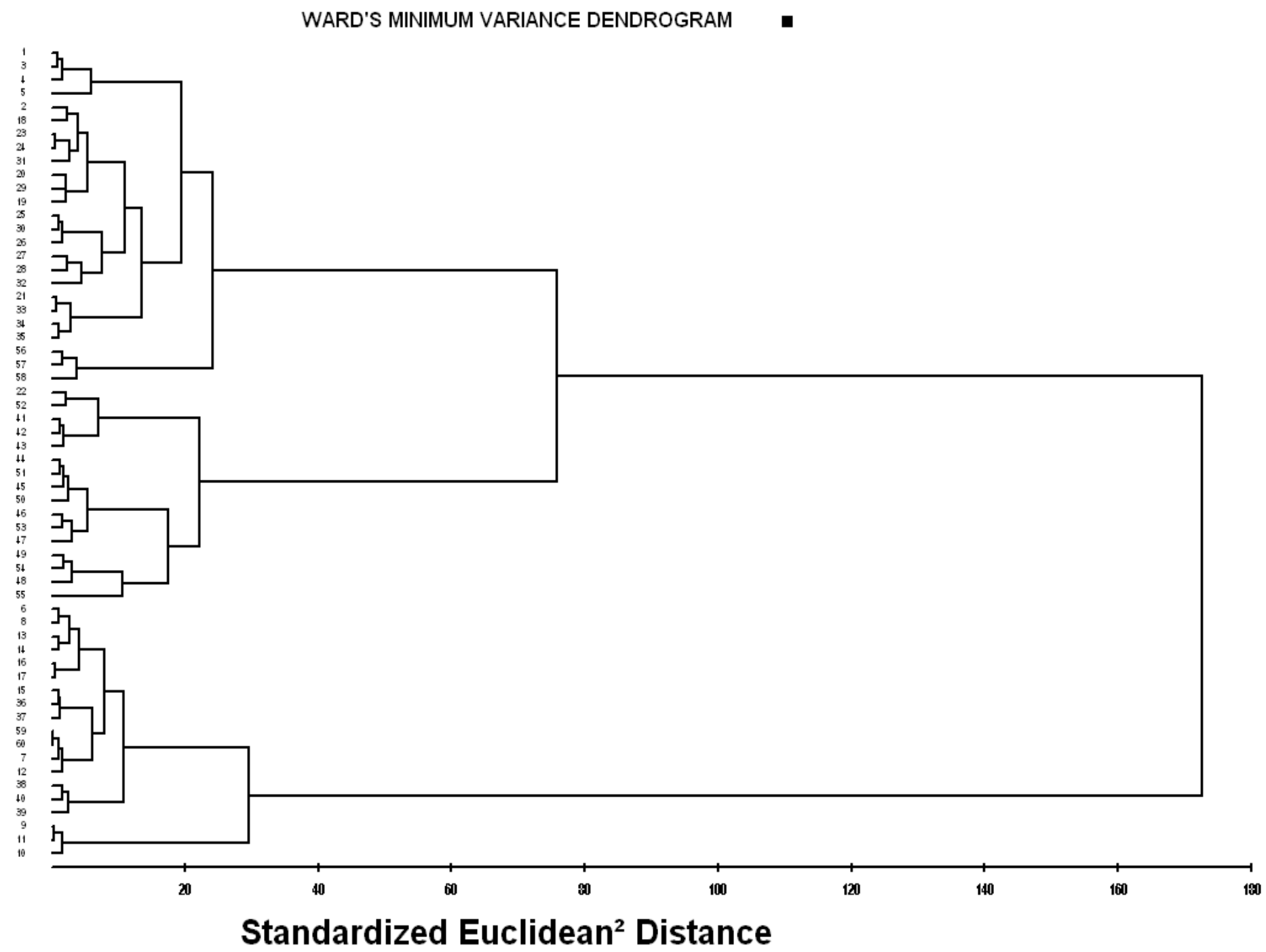


Similar results were reported by Zahid et al., (2008), Meena et al., (2010), Sefidan et al., (2014) in fennel and observed that the genetic diversity is not related to geographical variations necessarily. Similar results were confirmed by Wojo et al., (2015) in fenugreek and the cluster analysis suggested that there was considerable diversity among the germplasms and there is a very good scope to bring about improvement through hybridization and selection by crossing germplasms from different clusters. The number of times each of the eight characters appeared in first rank and its respective per cent contribution towards diversity is presented in table 3. Among all the characters studied, seed yield contributed maximum $(32.71 \%)$ to diversity by taking first rank 574 times, followed by number of umbels per plant $(31.75 \%)$ ranking 562 times first, plant height $(25.42 \%) 450$ ranking times first, umbellate per plant (5.75) with ranking 101 times first, number of secondary branches per plant $(2.15 \%)$ with ranking 38 times first, seeds per umbels $(1.58 \%)$ with ranking 28 times first, number of primary branches per plant $(0.45 \%)$ with ranking 8 times first and seeds per umbellate $(0.25 \%)$ with 4 ranking times first. Cluster means together information on the traits that contribute maximum towards divergence would help in selection of parents (Table 4). Among the genotypes of fennel, variability is high for seed yield, umbels per plant and plant height. Diversity of umbels per plant, umbellate per plant and plant height can be exploited for getting high yield and increase the yield level further. Salami et al., (2017) confirmed in the study of fennel genotypes that the high level of diversity and genetic distance beneficial for breeding proposes.

In conclusion, results of cluster analysis showed that there is no concordance between geographical resemblance and genetic diversity as the genotypes developed from different geographical region were included in the same clusters. The analysis suggested that there was considerable diversity among the germplasms. There is a very good scope to bring about improvement through hybridization and selection by crossing germplasms from different clusters. Present study suggests that selection of these traits could be effective in improving yield potential of fennel genotype and selection of diverse parents for purposeful hybridization will lead to the achievement of a breeding goal.

\section{References}

Meena, R.S., Kalkani, R.K., Anwar, M.M. and Panwar, A. 2010. Variability of some morphological characters in fennel. Indian J. Agri. Sci., 80: 710-712. Neamatollahi, E., BAnnayon, M., Ghanbari, A., Hayadari, M., and Ahmadian, A. 2009. Does hydro and osmo-priming impove fennel seed germination and seedling growth? Notulae Botanicae Horti Agroboctanici, 37(2): 19-194.

Salami, M., Rahimmalek, M. and Ehtemam, H.H. 2017. Genetic variability of outcross and selfed fennel based on morpholological and ISSR markers. $J$. Agri. Sci. Technol., 19: 157-172.

Sefidan Azam Yeganesh, Valizadeh Mostafa, Aharizad Saeed, and Sabzi Mohsen. 2014. Path analysis of grain yield, some morphological traits and essential contents in different fennel (Foeniculum vulgare Mill.) J. Biodiversity and Environ. Sci., 4(5): 10-15.

Spark, D.N. 1973. Euclidean Cluster Analysis. Algorithm As. 58. Appl. Statistics, 22: 126-130.

Ward, H.J. 1963. Hierarchical grouping to optimize an objective function. $J$. American Statistics Association, 58. 236-244.

Wojo Asebe, A., Alamerew Sentayehu 
Nebiyu Amsalu and Menamo Temesgen. 2015. Cluster analysis based on yield and yield components in fenugreek (Trigonella foenum-graceum L.) accessions. Global J. Sci. Frontier Res., 15(8): 41-45.

Zahid Najma Yousef, Abbasi Nadeem Akhtar,
Hafiz Ishfaq Ahmad and Ahmad Zahoor. 2008. Morphological charactereristics and oil contents of fennel (Foeniculum vulgare Mill.) accessions from different regions of Pakistan. J. Chem. Soc. Pak., 30(6): 889-895.

\section{How to cite this article:}

Sumit Deswal, T.P. Malik, S.K. Tehlan, Srikanth Mekala. 2017. Diversity Analysis Based Upon Yield and its Contributing Traits in Fennel (Foeniculum vulgare L.). Int.J.Curr.Microbiol.App.Sci. 6(7): 982-989. doi: https://doi.org/10.20546/ijcmas.2017.607.119 